\title{
Effect of Reduction Mammoplasty on Insulin and Lipid Metabolism in the Postoperative Third month: Compensatory Hip Enlargement
}

\author{
Soysal Bas ${ }^{1} \mathbb{1} \cdot$ Kurtulus $\mathrm{OZ}^{1} \cdot$ Anll Akkus $^{2} \cdot \operatorname{Mert~Sizmaz~}^{1} \cdot$ Erdinc Serin $^{2} \cdot$ \\ Mustafa Durgun ${ }^{3} \cdot$ Semra Karsidag ${ }^{1}$
}

Received: 8 March 2021 / Accepted: 9 May 2021 / Published online: 24 May 2021

(C) Springer Science+Business Media, LLC, part of Springer Nature and International Society of Aesthetic Plastic Surgery 2021

\begin{abstract}
Backgrounds The positive effects of reduction mammoplasty on metabolic profile have been shown in a limited number of studies. This study objective to reveal the effects of reduction mammoplasty on metabolic profile and anthropometric measurements.

Subjects and Method The study was prospectively conducted on 42 patients who were operated between April 2019 and March 2020. Fasting plasma glucose, fasting plasma insulin, total cholesterol, triglyceride, high-density lipoprotein and low-density lipoprotein cholesterol, $\mathrm{HgAlc}$, homeostasis model assessment scores, adiponectin, leptin, and resistin levels were evaluated. In addition, age, height, weight, body mass index; breast, chest, waist, hip circumference; waist-hip ratio, and bilateral breast resection tissue weights were recorded. Data and blood samples were collected one hour before the operation, 6 and 12 weeks after the operation.

Result The patients' mean age was $43.14 \pm 10.24$, and their average height was $159.42 \pm 4.96 \mathrm{~cm}$. The excised bilateral dermo fatty tissue weight was $1435.85 \pm 721.16 \mathrm{~g}$. At the postoperative 40th day a decrease in leptin $(p=0.001)$, resistin $(p=0.008)$, glucose $(p=0.021)$ and insulin resistance values $(p=0.013)$ stated. There was an increase in
\end{abstract}

Soysal Bas

soysalbas@gmail.com

1 Department of Plastic, Reconstructive and Aesthetic Surgery, University of Health Sciences, Sisli Hamidiye Etfal Training and Research Hospital, Istanbul, Turkey

2 Department of Biochemistry, Sisli Hamidiye Etfal Training and Research Hospital, Istanbul, Turkey

3 Department of Plastic, Reconstructive and Aesthetic Surgery, Private Clinic, Izmir, Turkey adiponectin $(p<0.001)$ and HDL $(p=0.013)$ levels at the postoperative 40th day. In the postoperative third month, these data returned to the previous levels that were measured before operations. However, an increase in hip circumference $(p=0.034)$ and a decrease in waist-hip ratio $(p<0.001)$ was detected in third month. Also, there was no difference in body mass index and weight compared to preoperation.

Conclusion After reduction mammoplasty, compensatory fat growth in the hip area, an increase in the hip circumference, and a decrease in the waist-hip ratio were observed in the postoperative third month.

Level of Evidence This journal requires that authors assign a level of evidence to each article. For a full description of these Evidence-Based Medicine ratings, please refer to the Table of Contents or the online Instructions to Authors www.springer.com/00266.

Keywords Reduction mammoplasty · Hip circumference · Waist-hip ratio

\section{Introduction}

Breast hypertrophy is an important clinical problem that causes neck and back pain, intertrigo underneath the breast folds, and restricts physical activities [1]. It can also be seen as a source of embarrassment by patients. This situation may lead to taking kyphotic posture to hide the breasts and psychological distress [2]. For these reasons, breast reduction surgery is among the procedures frequently performed by plastic surgeons. In 2018, breast reduction surgery was performed on approximately 84.600 patients in the USA [3]. 
Breast reduction provides a decrease in pains and an increase in physical activities [4]. Also, it provides a postural improvement resulting from a significant improvement in spinal angles such as cervical lordosis, thoracic kyphosis, and lumbar lordosis [5]. With the removal of excess breast tissue, chest wall compliance and ventilation increase, and respiratory function tests improve [6]. Besides all this physical improvement, breast reduction also improves body image and sexual functions [7, 8].

In addition to its lipid storage function, adipose tissue secretes many adipokines such as adiponectin, leptin, resistin, and proinflammatory cytokines. With these features, adipose tissue exhibits autocrine, paracrine, and endocrine effects. In this way, it plays a vital role in energy metabolism, insulin sensitivity, and inflammatory response [9]. Adiponectin increases glucose uptake and fatty acid oxidation; besides increased steatosis decreases adiponectin expression [10]. Leptin has a major role in the regulation of body weight, and its plasma level depends on the amount of subcutaneous adipose tissue [11]. On the other hand, resistin plays a major role in insulin resistance, inflammation, and more specifically vascular damage [12].

It is known that non-visceral upper body adipose tissue contributes to the metabolic complications of obesity [13]. Approximately $60 \%$ of breast tissue consists of adipose tissue. The presence of macromastia in adolescence is a predisposing factor for the development of type 2 diabetes mellitus in middle-aged individuals [14]. These data suggest that breast tissue may affect lipid and insulin metabolism. However, its effects on metabolic profile have been referred to in a limited number of studies [15-17]. This study aimed to reveal the effects of reduction mammoplasty on metabolic profile and anthropometric measurements.

\section{Subjects and Method}

This prospective self-controlled clinical trial was conducted on patients diagnosed of bilateral macromastia with clinical examination (back pain, neck pain, intertrigo around the breasts, bra strap marks). The study started after the approval of the local ethics committee and was conducted in accordance with the Helsinki Declaration (05.03.2019/2292). Informed consent was obtained from all patients. Non-smoker, non-pregnant patients who did not have any disease (such as diabetes, cardiovascular disease, thyroid dysfunction) and who did not have any prescription drug use and had a fixed weight in the last six months were included in the study. Patients who received medical or surgical treatment due to a new clinical diagnosis were excluded from the study. Patients under 40 years of age were evaluated with breast ultrasound, patients over 40 years of age were evaluated with mammography (mammogram) in the preoperative period. All imaging studies were reviewed by experienced radiologists, and patients with no risk of breast cancer were operated. In addition, patients with wound infection, pedicle or skin necrosis, and wound healing problems in the postoperative period were excluded from the study. Also, it was strictly advised not to change the preoperative diet regimen and to postpone the exercise programs until the data collection process was completed. Between April 2019 and March 2020, 52 patients underwent reduction mammoplasty. The study was conducted on 42 patients who met the inclusion criteria and did not change their preoperative diet and exercise regimen. 6 of 10 patients who were excluded from the study did not come to postoperative controls (due to the Covid-19 pandemic). Three patients were excluded from the study because of postoperative wound detachment, and one patient because of hematoma. The data were obtained from the results of blood taken, and anthropometric measurements were done one hour before the operation, $40 \pm 2$ days and $90 \pm 2$ days postoperatively.

\section{Laboratory Analysis}

Blood collection procedures were carried out through venous vessels. Blood was drawn in the morning after 12 hours of fasting. Blood was drawn into a $2 \mathrm{~mL}$ empty biochemistry tube to measure fasting plasma glucose, fasting plasma insulin, total cholesterol, triglyceride, highdensity lipoprotein cholesterol (HDL), and low-density lipoprotein cholesterol (LDL) levels. Venous blood was collected in $1 \mathrm{~mL}$ tube with anticoagulant for $\mathrm{HgAlc}$ measurement (preoperatively and at the third month postoperatively). Blood samples were studied in the biochemistry laboratory on the day of collection. Insulin sensitivity was calculated using the homeostasis model assessment index (HOMA-IR, plasma glucose level $\times$ (plasma insulin level)/22.5), and a value greater than 2.5 was accepted as insulin resistance [18].

In order to measure adiponectin, leptin, and resistin values, $2 \mathrm{~mL}$ of venous blood was drawn into an empty biochemistry tube. Tubes were centrifuged at $3000 \mathrm{rpm}$ for 10 minutes. Serum parts separated to the Eppendorf tubes and stored at $-20^{\circ} \mathrm{C}$. Hemolyzed samples were excluded from the study. After the sample collection was completed, the serums were brought to room temperature to be studied. Adiponectin, leptin, and resistin were measured by enzyme-linked immunosorbent assay after 60 minutes of incubation at $37^{\circ} \mathrm{C}$ (Human adiponectin, leptin, resistin ELISA kit, Bioassay Technology Laboratory, Shanghai, China). The assay was performed according to the manufacturer's instructions manual. The intra-assay and interassay coefficients of variation for adiponectin, leptin and 
resistin were $4.8-5.1 \%$ and $6.5-7.2 \%, 5.1-6.8 \%$ and $5.4-6.9 \%, 5.2-7.4 \%$ and $6.1-7.4 \%$ consecutively.

\section{Demographic Data and Anthropometric Measurements}

Anthropometric measurements were made with an inelastic tape measure after 12 hours of the fasting period, at the end of expiration, and in a standing position. Data were age, height, weight, body mass index (BMI: weight/the square of height), breast circumference (measured at the level of the nipple), chest circumference (measured at the level of the inframammary fold), waist circumference (measured at the level of the transverse umbilical line), hip circumference (measured at the level of the intertrochanteric line), waist-hip ratio (WHR) and bilaterally resected breast tissue weight.

\section{Surgical and Postoperative Procedures}

All patients were operated on under general anesthesia. The preferred technique was superomedial pedicle inverted-T pattern reduction mammoplasty. Excised tissues were sent for histopathological examination. Surgical vacuum drains were removed when drainage fluid was below $25 \mathrm{~mL}$ per 24 hours. Patients were discharged with $500 \mathrm{mg}$ first-generation cephalosporin twice a day for five days. Trunk elevation was recommended for two weeks after the surgery, and a compression bra was applied for the 1st month.

\section{Statistical Analysis}

SPSS software for Windows (version 26.0; IBM Corporation, Armonk, New York, USA) was used for statistical analysis. Data were defined as the frequency and percentage for categorical variables, the mean and standard deviation for numerical variables. Kolmogorov-Smirnov test was used for normality analysis. When the number of dependent groups was more than two, the repeated-measures ANOVA test and the Friedman test were used for analysis. Paired t test and Wilcoxon rank-sum test were used to compare the two dependent groups. The relationship between the excised dermo fatty tissue and data differences was evaluated using Pearson's correlation test and Spearman's rho test. The statistical significance level was accepted as $p<0.05$.

\section{Results}

The average age of the patients was $43.14 \pm 10.24$ years, and the average height of the patients was $159.42 \pm 4.96$ $\mathrm{cm}$. The bilaterally excised dermo fatty tissue weight was $1435.85 \pm 721.16 \mathrm{~g}$.
The data obtained from blood results and anthropometric measurements are presented in Table 1. Total cholesterol, triglyceride, LDL, HgA1c levels, chest and waist circumferences were not affected by reduction mammoplasty operation considering 40th day and thirdmonth results postoperatively.

Although reduction mammoplasty operation ensured improvement in metabolic profile on the 40th day postoperatively, this effect was not continued in the third month. Mean serum levels of adiponectin increased on the 40th day compared to the preoperative period (3.26 \pm 5.49 , $p<0.001)$, though it was similar to the preoperative period at the third month $(0.07 \pm 6.07, p=0.731)$. Mean leptin levels were decreased on the 40th day $(-1.88 \pm 3.57, p=$ $0.001)$, but again it was similar to the preoperative period at the third month $(-0.47 \pm 3.85, p=0.730)$. Resistin levels decreased like leptin on the 40th day $(-0.61 \pm 2.46, p=$ 0.008 ) and returned to their previous levels at the third month $(0.34 \pm 3.01, p=0.788)$. At the 40th day postoperatively, an increase in HDL levels $(3.92 \pm 9.85, p=0.013)$ a decrease in glucose $(-0.10 \pm 0.81, p=0.021)$, plasma insulin $(-2.08 \pm 5.92, p=0.024)$ and insulin resistance (HOMA-IR; -- $0.58 \pm 1.47, p=0.013$ ) values were stated compared to the preoperative period. These values returned to their preoperative levels at the third month postoperatively (Table 2).

The net effect of reduction mammoplasty was clearer on anthropometric measurements. Bodyweight $(-1.52 \pm 1.83$, $p<0.001)$ and BMI $(-0.60 \pm 0.72, p<0.001)$ decreased on the 40th day after surgery, nevertheless both of them returned to their previous rates in the third-month measurements. Breast circumference decreased as expected on 40th day $(-3.76 \pm 5.09, p<0.001)$ and at third-month measurements $(-4.35 \pm 4.48, p<0.001)$. Hip circumference gradually increased at 40th day and third-month measurements $(2.90 \pm 4.69, p<0.001)$. Waist-hip ratio decreased on the 40th day $(-0.02 \pm 0.07, p=0.034)$ and at the third month measurements $(-0.04 \pm 0.08, p<0.001)$. (Table 3).

There is a positive correlation between excised dermo fatty tissue weight and breast circumference at the third month postoperatively ( $r=0.515, p<0.001)$. Furthermore, excised dermo fatty tissue weight has positive correlation with waist-hip ratio $(r=0.321, p=0.038)$ and negative correlation with hip circumference $(r=-0.345, p=0.027)$ (Table 4).

\section{Discussion}

In this study, serum adiponectin, leptin, resistin levels, and plasma lipid profile were studied to evaluate the effect of reduction mammoplasty on lipid metabolism. In order to 
Table 1 Metabolic parameters and demographic data in preoperative, postoperative 40th day, and postoperative third month.

\begin{tabular}{|c|c|c|c|c|}
\hline & Preoperative Mean \pm SD & Postoperative 40. Day Mean \pm SD & Postoperative 3 . Month Mean \pm SD & $P$ \\
\hline Adiponectin, $\mu \mathrm{g} / \mathrm{mL}$ & $16.47 \pm 9.87$ & $19.74 \pm 10.95$ & $16.55 \pm 10.16$ & $0.004^{\mathrm{a}}$ \\
\hline Leptin, ng/mL & $13.20 \pm 6.52$ & $11.31 \pm 5.24$ & $12.72 \pm 6.69$ & $0.009^{\mathrm{a}}$ \\
\hline Resistin, ng/mL & $1.25 \pm 0.73$ & $1.19 \pm 0.81$ & $1.29 \pm 0.81$ & $\mathbf{0 . 0 2 3}^{\mathrm{a}}$ \\
\hline Total cholesterol, mg/dL & $218.92 \pm 39.07$ & $218.00 \pm 39.39$ & $218.90 \pm 39.53$ & $0.662^{\mathrm{b}}$ \\
\hline Triglycerides, mg/dL & $105.09 \pm 51.97$ & $102.21 \pm 26.16$ & $106.90 \pm 34.54$ & $0.765^{\mathrm{a}}$ \\
\hline $\mathrm{LDL}, \mathrm{mg} / \mathrm{dL}$ & $143.28 \pm 30.56$ & $142.09 \pm 33.18$ & $142.09 \pm 35.74$ & $0.940^{\mathrm{b}}$ \\
\hline $\mathrm{HDL}, \mathrm{mg} / \mathrm{dL}$ & $53.71 \pm 10.47$ & $57.64 \pm 11.80$ & $54.97 \pm 8.68$ & $0.009^{b}$ \\
\hline Glucose, $\mathrm{mmol} / \mathrm{L}$ & $5.32 \pm 0.67$ & $5.28 \pm 0.66$ & $5.23 \pm 0.71$ & $0.645^{b}$ \\
\hline Insulin, $\mu \mathrm{U} / \mathrm{mL}$ & $11.08 \pm 4.77$ & $9.00 \pm 3.58$ & $10.92 \pm 4.40$ & $0.041^{\mathrm{a}}$ \\
\hline HOMA-IR* score & $2.66 \pm 1.32$ & $2.07 \pm 0.85$ & $2.55 \pm 1.13$ & $0.049^{\mathrm{a}}$ \\
\hline $\operatorname{HgA} 1 \mathrm{c}(\%)$ & $5.45 \pm 0.48$ & - & $5.47 \pm 0.65$ & $0.609^{c}$ \\
\hline Weight, kg & $75.85 \pm 10.98$ & $74.33 \pm 10.46$ & $75.11 \pm 11.86$ & $<0.001^{\mathrm{a}}$ \\
\hline BMI, $\mathrm{kg} / \mathrm{m}^{2}$ & $29.86 \pm 4.28$ & $29.26 \pm 4.05$ & $29.58 \pm 4.64$ & $<0.001^{\text {b }}$ \\
\hline Breast circumference, $\mathrm{cm}$ & $107.30 \pm 8.32$ & $103.54 \pm 8.50$ & $102.92 \pm 7.83$ & $<\mathbf{0 . 0 0 1}^{\mathrm{b}}$ \\
\hline Chest circumference, $\mathrm{cm}$ & $95.38 \pm 7.95$ & $95.45 \pm 8.30$ & $94.83 \pm 9.91$ & $0.594^{\mathrm{b}}$ \\
\hline Waist circumference, $\mathrm{cm}$ & $104.09 \pm 9.58$ & $102.47 \pm 10.89$ & $102.33 \pm 8.47$ & $0.170^{\mathrm{b}}$ \\
\hline Hip circumference, $\mathrm{cm}$ & $107.52 \pm 8.79$ & $108.76 \pm 9.68$ & $110.42 \pm 8.04$ & $\mathbf{0 . 0 0 1}^{\mathrm{b}}$ \\
\hline Waist-hip ratio & $0.96 \pm 0.05$ & $0.94 \pm 0.08$ & $0.92 \pm 0.06$ & $0.016^{b}$ \\
\hline
\end{tabular}

The bold symbols indicate statistical significance $p<0.05$

${ }^{a}$ The repeated-measures ANOVA test.

${ }^{\mathrm{b}}$ Friedman test.

${ }^{c}$ Wilcoxon rank-sum test.

*Homeostasis model assessment scores.

Table 2 Differences and statistical relationship of postoperative and preoperative blood values.

\begin{tabular}{lcccccc}
\hline & \multicolumn{2}{c}{ Postoperative 40. day-Preoperative } & & \multicolumn{2}{c}{ Postoperative 3. month-Preoperative } \\
\cline { 2 - 3 } & Difference Mean \pm SD & $p$ & & Difference Mean \pm SD & $p$ \\
\hline Adiponectin, $\mu \mathrm{g} / \mathrm{mL}$ & $3.26 \pm 5.49$ & $<0.001^{\mathrm{a}}$ & & $0.07 \pm 6.07$ & $0.731^{\mathrm{a}}$ \\
Leptin, $\mathrm{ng} / \mathrm{mL}$ & $-1.88 \pm 3.57$ & $0.001^{\mathrm{a}}$ & & $-0.47 \pm 3.85$ & $0.730^{\mathrm{a}}$ \\
Resistin, $\mathrm{ng} / \mathrm{mL}$ & $-0.61 \pm 2.46$ & $0.008^{\mathrm{a}}$ & & $0.34 \pm 3.01$ & $0.788^{\mathrm{a}}$ \\
HDL, $\mathrm{mg} / \mathrm{dL}$ & $3.92 \pm 9.85$ & $0.013^{\mathrm{b}}$ & & $1.2 \pm 6.98$ & $0.249^{\mathrm{b}}$ \\
Glucose, $\mathrm{mmol} / \mathrm{L}$ & $-0.10 \pm 0.81$ & $0.021^{\mathrm{b}}$ & & $-0.86 \pm 0.78$ & $0.053^{\mathrm{b}}$ \\
Insulin, $\mu \mathrm{U} / \mathrm{mL}$ & $-2.08 \pm 5.92$ & $0.024^{\mathrm{a}}$ & & $-0.15 \pm 6.28$ & $0.896^{\mathrm{a}}$ \\
HOMA-IR score* & $-0.58 \pm 1.47$ & $0.013^{\mathrm{a}}$ & & $-0.10 \pm 1.65$ & $0.676^{\mathrm{a}}$ \\
\hline
\end{tabular}

${ }^{\text {a }}$ Paired $t$ test.

${ }^{b}$ Wilcoxon rank-sum test.

*Homeostasis model assessment scores. evaluate their effects on insulin metabolism, plasma glucose and insulin levels were measured, and insulin resistance was calculated. Also, anthropometric measurements were taken to evaluate body fat distribution. The preoperative data were compared with the postoperative 40th and 90th days data.

Uzun et al. performed reduction mammoplasty on 42 obese patients (BMI, $33.94 \pm 2.39$ ). They resected an average of $1954.43 \pm 505.81 \mathrm{~g}$ of dermo fatty tissue. They demonstrated a decrease in BMI, leptin level, and insulin resistance in the postoperative second month [16]. Vanci et al. performed reduction mammoplasty on 27 patients who were borderline obese (BMI, $30.5 \pm 6.86$ ) and resected an average of $1732.2 \pm 796.65 \mathrm{~g}$ of dermo fatty tissue from these patients. They determined an increase in adiponectin and HDL levels and a decrease in glucose levels on the postoperative 40th day. In the same study, they did not state any change in BMI and WHR [17]. In this study, 
Table 3 Differences and statistical relationship of postoperative and preoperative anthropometric values.

\begin{tabular}{llllll}
\hline & \multicolumn{2}{l}{ Postoperative 40. day-Preoperative } & & \multicolumn{2}{l}{ Postoperative 3. month-Preoperative } \\
\cline { 2 - 2 } & Difference Mean \pm SD & $p$ & & Difference Mean \pm SD & $p$ \\
\hline Weight, $\mathrm{kg}$ & $-1.52 \pm 1.83$ & $\mathbf{< 0 . 0 0 1}^{\mathbf{a}}$ & & $-0.73 \pm 4.81$ & $0.130^{\mathbf{a}}$ \\
BMI, $\mathrm{kg} / \mathrm{m}^{2}$ & $-0.60 \pm 0.72$ & $\mathbf{< . 0 0 1}^{\mathbf{b}}$ & $-0.28 \pm 1.90$ & $0.141^{\mathbf{b}}$ \\
Breast circumference, cm & $-3.76 \pm 5.09$ & $\mathbf{< . 0 0 1}^{\mathbf{b}}$ & $-4.35 \pm 4.68$ & $\mathbf{0 . 0 0 1}^{\mathbf{b}}$ \\
Hip circumference, cm & $1.23 \pm 4.77$ & $0.101^{\mathbf{b}}$ & & $2.90 \pm 4.69$ & $\mathbf{0 . 0 0 1}^{\mathbf{b}}$ \\
Waist-hip ratio, cm & $-0.02 \pm 0.07$ & $\mathbf{0 . 0 3 4}^{\mathbf{b}}$ & $-0.04 \pm 0.08$ & $\mathbf{0 . 0 0 4}^{\mathbf{b}}$ \\
\hline
\end{tabular}

The bold symbols indicate statistical significance $p<0.05$

${ }^{a}$ Paired t test.

${ }^{\mathrm{b}}$ Wilcoxon rank-sum test.

Table 4 Association between fat removed and data that preoperative and postoperative difference.

\begin{tabular}{|c|c|c|c|c|}
\hline & \multicolumn{2}{|c|}{ Postoperative 40. day - Preoperative Difference } & \multicolumn{2}{|c|}{ Postoperative 3. month - Preoperative Difference } \\
\hline & $r$ & $p$ & $r$ & $p$ \\
\hline Adiponectin & 0.140 & $0.376^{\mathrm{b}}$ & 0.227 & $0.148^{\mathrm{b}}$ \\
\hline Leptin & 0.028 & $0.860^{\mathrm{a}}$ & 0.167 & $0.292^{\mathrm{a}}$ \\
\hline Resistin & -0.023 & $0.886^{\mathrm{a}}$ & 0.140 & $0.378^{\mathrm{a}}$ \\
\hline Triglycerides & 0.070 & $0.657^{\mathrm{b}}$ & 0.023 & $0.887^{\mathrm{a}}$ \\
\hline HDL & 0.251 & $0.109^{\mathrm{b}}$ & 0.237 & $0.080^{\mathrm{b}}$ \\
\hline Glucose & 0.477 & $\mathbf{0 . 0 0 1}^{\mathrm{b}}$ & 0.52 & $0.744^{\mathrm{b}}$ \\
\hline Insulin & -0.087 & $0.583^{\mathrm{b}}$ & -0.006 & $0.969^{\mathrm{b}}$ \\
\hline HOMA-IR* score & 0.085 & $0.592^{\mathrm{b}}$ & -0.078 & $0.622^{\mathrm{a}}$ \\
\hline Weight & 0.175 & $0.267^{\mathrm{a}}$ & -0.287 & $0.066^{\mathrm{a}}$ \\
\hline BMI & 0.154 & $0.330^{\mathrm{b}}$ & -0.191 & $0.225^{\mathrm{b}}$ \\
\hline Breast circumference & 0.405 & $\mathbf{0 . 0 0 8}^{\mathrm{b}}$ & 0.515 & $<0.001^{b}$ \\
\hline Waist circumference & 0.047 & $0.766^{\mathrm{b}}$ & 0.056 & $0.856^{\mathrm{b}}$ \\
\hline Hip circumference & -0.110 & $0.490^{\mathrm{b}}$ & -0.345 & $0.027^{\mathrm{a}}$ \\
\hline Waist-hip ratio & 0.116 & $0.464^{\mathrm{b}}$ & 0.321 & $\mathbf{0 . 0 3 8}^{\mathrm{b}}$ \\
\hline
\end{tabular}

The bold symbols indicate statistical significance $p<0.05$

${ }^{\text {a }}$ Spearman's rho test.

bearson's correlation test.

*Homeostasis model assessment scores

removal of breast tissue by reduction mammoplasty provided metabolic improvement on the 40th day postoperatively. The decrease in leptin, resistin, glucose values, and insulin resistance, and increase in adiponectin and HDL levels was stated. Unlike these studies, metabolic improvements were not detected in our study in the thirdmonth controls.

In the early period after reduction mammoplasty, weight loss and improvement in BMI were observed due to the removal of dermo fatty tissue. However, when evaluated for a long period of time, many studies have shown that reduction mammoplasty did not improve weight and BMI. Rinomota et al. reported that patients who underwent abdominoplasty $(n=16)$ and reduction mammoplasty $(n=17)$ gained weight at the 18th month after surgery.
They also stated that lipectomy had limited effects on weight loss [19]. Singh et al. observed patients who underwent breast reduction for two years. It was found out during the follow-up that the operation caused weight loss in the group of patients who thought that the operation was motivating for weight loss and weight increase in the group of patients who thought it would not be motivating [20]. Sarıc1 et al. stated no significant difference in weight and BMI of the 62 patients who underwent reduction mammoplasty in the postoperative third month [14]. In our study, a decrease in BMI and weight loss was detected on the postoperative 40th day. However, it was determined that reduction mammoplasty did not reduce weight and $\mathrm{BMI}$ in the third month. 
For many years, it was believed that in humans, the number of adipocytes was stable. Therefore, the human body was reacting to weight gain and loss by changing adipocyte cell size rather than cell number [21]. Recent studies have proven that the adipocyte turnover rate varies between 10 and 100\% [22, 23]. In 2001, Mauer et al. applied lipectomy to different regions in ground squirrels and showed that adipocyte levels were restored in areas where lipectomy was not performed [24]. In humans, breast enlargement after abdominal liposuction due to compensatory adipose tissue growth has been pointed out in many studies [25-27].

Tchoukalova et al. have performed a study on 28 healthy adult volunteers. They stated that the increase in subcutaneous fatty tissue occurred in 2 months with overfeeding. Abdominal and upper body adipocytes reacted to overfeeding with hypertrophy, besides lower body adipocytes reacted with hyperplasia. Hyperplasia in lower body fatty tissue may contribute to the prevention of fatty tissue accumulation in the upper body. Also, hyperplasia of lower body adipocytes may prevent lipid accumulation in visceral organs [28]. In this study, there is a statistically significant negative correlation between excised dermo fat tissue amount and hip circumference in the postoperative third month. Measurements have shown that body fat distribution has changed, and lower body subcutaneous fatty tissue has increased. These findings have given rise to thought that reduction mammoplasty has caused compensatory hip enlargement in postoperative third month.

In this study, to maximize the effect of reduction mammoplasty on fat metabolism, it was suggested that patients should not change their diet regimen and physical activity after the operation. During the short 40-day time interval, the patients' physiology is recovering from surgery and not just responding to the reduction in breast fat/parenchyma. The patient's physiology responds to the assault of surgery itself: Anesthetic response, trauma response, pain, and wound healing. Therefore, the observed metabolic parameters and anthropometric values cannot be attributed to fat reduction alone. Although approximately $1500 \mathrm{~g}$ of dermo fat tissue was removed from the patients, there was no change in BMI and weight in the postoperative third month. The most important factor that explains this situation seems to be the compensation of the upper body fat mass, which is surgically removed, with the hip region fat mass. Also, we think that the decrease in breast circumference on the 90th day compared to the 40th day is due to the regression of edema secondary to the operation. Changes in body fat distribution after lipectomy are not a new finding. However, the most important finding that distinguishes this study from other studies is that it is shown that the distribution of fat after breast reduction is shaped in the direction of the lower body.
It is known that central obesity increases insulin resistance and its related complications. In the meta-analysis in which approximately 83 thousand patients were evaluated, greater WHR showing central obesity was associated with cardiovascular disease and associated mortality. In the same study, BMI, which is an indicator of global obesity, was not associated with cardiovascular disease [29]. Increased hip circumference, especially in women, has protective effects against obesity-related coronary artery disease and cardiovascular disease [30, 31]. In addition, large hip and thigh circumferences reduce the risk of type 2 diabetes regardless of age, BMI, and waist circumference [32]. The results of this study suggest that reduction mammoplasty increases hip circumference and decreases WHR. Consequently, reduction mammoplasty may reduce the risk of cardiovascular disease and type 2 diabetes.

This study has some limitations. Although compensatory hip enlargement after reduction mammoplasty has not been demonstrated previously, larger sample size and longer follow-up periods will strengthen the data. Patients included in the study were healthy adults. If the studies were conducted in morbid obese or diabetic patients, possible direct positive effects of reduction mammoplasty could have been revealed. Plus, body fat distribution was defined by anthropometric measurements. Although there is a strong correlation between anthropometric measurements and dual-energy X-ray absorptiometry and computed tomography, obtaining more quantitative data with the latter two methods will increase the level of evidence of the study [33]. Finally, it could have been an important input in this study to demonstrate the effect of reduction mammoplasty on feminine hormones (estrogen, progesterone, prolactin, follicular stimulating, and luteinizing hormone) and the reduction of risks associated with a possible decrease in their levels. However, these hormone levels change in the premenopausal and postmenopausal periods, and in premenopausal patients, the duration of blood collection varies according to ovulation and menstrual cycle. We thought that the inclusion of these hormones in the study would decrease the continuity of the study as it would increase the number of visits and blood draws, and statistical power would decrease with increasing the groups. We also did not have enough funds to study feminine hormones. Therefore, we have considered evaluating feminine hormones in a separate study.

\section{Conclusion}

Although there was no metabolic and biochemical improvement after reduction mammoplasty in the postoperative third month, body fat distribution has changed. 
Compensatory fatty tissue growth in the hip area increased hip circumference and decreased the WHR.

Funding This study was funded by the University of Health Sciences, Scientific Research Projects Unit. The authors declare that they have no conflict of interest.

\section{Declarations}

Conflict of interest The authors declare that they have no conflict of interest.

Ethical Approval "All procedures performed in studies involving human participants were in accordance with the ethical standards of the institutional and/or national research committee and with the 1964 Helsinki declaration and its later amendments or comparable ethical standards." The study started after the approval of the local ethics committee (05.03.2019/2292)

Informed Consent Informed consent was obtained from all patients involved.

\section{References}

1. Pauzenberger R, Bauer T, Kirchebner M, Pikula R, Verstappen R, Mühlbacher J, Djedovic G, Pierer G, Rieger UM (2014) Reduction mammaplasty: outcome analysis based on bodyweight. Aesthet Plast Surg 38:120-128

2. Mazzocchi M, Dessy LA, Di Ronza S, Iodice P, Saggini R, Scuderi N (2012) A study of postural changes after breast reduction. Aesthet Plast Surg 36:1311-1319

3. Waltho D, Gallo L, Gallo M, Murphy J, Copeland A, Mowakket S, Moltaji S, Baxter C, Karpinski M, Thoma A (2020) Outcomes and outcome measures in breast reduction mammaplasty: a systematic review. Aesthet Surg J 40:383-391

4. Rogliani M, Gentile P, Labardi L, Donfrancesco A, Cervelli V (2012) Improvement of physical and psychological symptoms after breast reduction. J Plast Reconstr Aesthet Surg 62:1647-1649

5. Berberoglu O, Temel M, Turkmen A (2015) Effects of reduction mammaplasty operations on the spinal column: clinical and radiological response. Aesthet Plast Surg 39:514-522

6. Ceber M, Yuksek A, Mutlu LC, Bali I, Topcu B (2015) Reduction mammaplasty effect on pulmonary function and arterial blood gas in the overweight female. Aesthet Plast Surg 39:540-546

7. Fonseca CC, Veiga DF, Garcia EDS, Cabral IV, de Carvalho MM, de Brito MJA, Ferreira LM (2018) Breast hypertrophy, reduction mammaplasty, and body image. Aesthet Surg J 38:972-979

8. Janik PE, Charytonowicz D, Miszczyk J, Charytonowicz M (2019) Female sexual function and sexual well-being before and after breast reduction: a pilot cross-sectional study and review of literature. Ann Plast Surg 82:609-613

9. Yadav A, Kataria MA, Saini V, Yadav A (2013) Role of leptin and adiponectin in insulin resistance. Clin Chim Acta 417:80-84

10. Fasshauer M, Klein J, Kralisch S, Klier M, Lössner U, Blüher M, Paschke R (2004) Growth hormone is a positive regulator of adiponectin receptor 2 in 3T3-L1 adipocytes. FEBS Lett 558:27-32

11. Friedman J (2002) Fat in all the wrong places. Nature 415:268-269
12. Spoto B, Mattace-Raso F, Sijbrands E, Pizzini P, Cutrupi S, D’Arrigo G, Tripepi G, Zoccali C, Mallamaci F (2013) Resistin and all-cause and cardiovascular mortality: effect modification by adiponectin in end-stage kidney disease patients. Nephrol Dial Transplant. https://doi.org/10.1093/ndt/gft365

13. Vazquez G, Duval S, Jacobs DR Jr, Silventoinen K (2007) Comparison of body mass index, waist circumference, and waist/ hip ratio in predicting incident diabetes: a meta-analysis. Epidemiol Rev 29:115-128

14. Ray JG, Mohllajee AP, van Dam RM, Michels KB (2008) Breast size and risk of type 2 diabetes mellitus. CMAJ 178:289-295

15. Sarıc1 M, Demirseren ME, Durgun M, Ceran C, Yenidunya MO (2011) Effects of reduction mammoplasty on metabolic profile and body weight. Aesthet Plast Surg 35:995-999

16. Uzun H, Bitik O, Baltu Y, Sönmez Ç, Öztürk Kaymak A (2015) The Effects of reduction mammaplasty on serum leptin levels and insulin resistance. Int J Endocrinol 2015:719824

17. Vinci V, Valaperta S, Klinger M, Montanelli A, Specchia C, Forcellini D, Maione L, Klinger FM, Caviggioli F (2016) Metabolic implications of surgical fat removal: increase of adiponectin plasma levels after reduction mammaplasty and abdominoplasty. Ann Plast Surg 76:700-704

18. Spoto B, Mattace-Raso F, Sijbrands E, Pizzini P, Cutrupi S, D'Arrigo G, Tripepi G, Zoccali C, Mallamaci F (2013) Resistin and all-cause and cardiovascular mortality: effect modification by adiponectin in end-stage kidney disease patients. Nephrol Dial Transplant 28:181-187

19. Rinomhota AS, Bulugahapitiya DU, French SJ, Caddy CM, Griffiths RW, Ross RJ (2008) Women gain weight and fat mass despite lipectomy at abdominoplasty and breast reduction. Eur J Endocrinol 158:349-352

20. Singh KA, Pinell XA, Losken A (2010) Is reduction mammaplasty a stimulus for weight loss and improved quality of life? Ann Plast Surg 64:585-587

21. Hyvönen MT, Spalding KL (2014) Maintenance of white adipose tissue in man. Int J Biochem Cell Biol 56:123-132

22. Strawford A, Antelo F, Christiansen M, Hellerstein MK (2004) Adipose tissue triglyceride turnover, de novo lipogenesis, and cell proliferation in humans measured with $2 \mathrm{H} 2 \mathrm{O}$. Am J Physiol Endocrinol Metab 286:E577-E588

23. Spalding KL, Arner E, Westermark PO, Bernard S, Buchholz BA, Bergmann O, Blomqvist L, Hoffstedt J, Näslund E, Britton T, Concha H, Hassan M, Rydén M, Frisén J, Arner P (2008) Dynamics of fat cell turnover in humans. Nature 453:783-787

24. Mauer MM, Harris RB, Bartness TJ (2001) The regulation of total body fat: lessons learned from lipectomy studies. Neurosci Biobehav Rev 25:15-28

25. Finzi E (2003) Breast enlargement induced by liposuction. Dermatol Surg 29:928-930

26. Frew KE, Rossi A, Bruck MC, Katz BE, Narins RS (2005) Breast enlargement after liposuction: comparison of incidence between power liposuction versus traditional liposuction. Dermatol Surg 31:292-296

27. van der Lei B, Halbesma GJ, van Nieuwenhoven CA, van Wingerden JJ (2007) Spontaneous breast enlargement following liposuction of the abdominal wall: does a link exist? Plast Reconstr Surg 119:1584-1589

28. Tchoukalova YD, Votruba SB, Tchkonia T, Giorgadze N, Kirkland JL, Jensen MD (2010) Regional differences in cellular mechanisms of adipose tissue gain with overfeeding. Proc Natl Acad Sci U S A 107:18226-18231

29. Czernichow S, Kengne AP, Stamatakis E, Hamer M, Batty GD (2011) Body mass index, waist circumference and waist-hip ratio: which is the better discriminator of cardiovascular disease mortality risk?: evidence from an individual-participant meta- 
analysis of 82864 participants from nine cohort studies. Obes Rev 12(9):680-687

30. Lissner L, Björkelund C, Heitmann BL, Seidell JC, Bengtsson C (2001) Larger hip circumference independently predicts health and longevity in a Swedish female cohort. Obes Res 9:644-646

31. Heitmann BL, Frederiksen P, Lissner L (2004) Hip circumference and cardiovascular morbidity and mortality in men and women. Obes Res 12:482-487

32. Snijder MB, Dekker JM, Visser M, Bouter LM, Stehouwer CD, Kostense PJ, Yudkin JS, Heine RJ, Nijpels G, Seidell JC (2003) Associations of hip and thigh circumferences independent of waist circumference with the incidence of type 2 diabetes: the Hoorn Study. Am J Clin Nutr 77:1192-1197

33. Kaul S, Rothney MP, Peters DM, Wacker WK, Davis CE, Shapiro MD, Ergun DL (2012) Dual-energy X-ray absorptiometry for quantification of visceral fat. Obesity (Silver Spring) 20:1313-1318

Publisher's Note Springer Nature remains neutral with regard to jurisdictional claims in published maps and institutional affiliations. 